\title{
Atnalı Böbreklerde Perkütan Nefrolitotomi Deneyimlerimiz
}

\author{
Our Experience on Percutaneous Nephrolithotomy in Horseshoe Kidney
}

\author{
Hüseyin Aydemir, Salih Budak, Fikret Halis, Deniz Gül, Hacı İ. Çimen, Osman Köse, \\ Hasan S. Sağlam, Ahmet Gökçe
}

Sakarya Üniversitesi Tip Fakültesi Eğitim Ve Araştırma Hastanesi, Üroloji Kliniği, Sakarya/ TÜRKİYE

Yazış̧ma Adresi / Correspondence:

Hüseyin Aydemir

Sakarya Üniversitesi Tip Fakültesi Eğitim Ve Araştırma Hastanesi, Üroloji Kliniği, Sakarya, Türkiye

T: +90505 2760650 E-mail: : husaydemir@yahoo.com

Geliş Tarihi / Received : 12.03.2019 Kabul Tarihi / Accepted : 20.05.2019

Orcid :

Hüseyin Aydemir: https://orcid.org/0000-0003-4048-7311

Hacı İ. Çimen: https://orcid.org/0000-0002-0824-3926

Salih Budak: https://orcid.org/0000-0001-5130-4483

Ahmet Gökçe: https://orcid.org/0000-0001-7776-1893

Osman Köse: https://orcid.org/0000-0002-1053-3551

Fikret Halis: https://orcid.org/0000-0003-2613-6398

Hasan Salih Sağlam: https://orcid.org/0000-0002-5638-2269

Deniz Gül: https://orcid.org/0000-0003-0873-0000

\footnotetext{
$\ddot{\mathrm{O} z}$

Amaç Atnalı böbrek, renal füzyon anomalilerinin en yaygın görülen tipidir. En sık görülen komplikasyonu ise böbrek taşlardır. Bu çalışmanın amacı, atnalı böbrek anomalisi olan hastalarda, renal taşların tedavisinde uygulanan perkütan nefrolitotomi (PNL) cerrahisinin sonuçlarını değerlendirmektir. . ( Sakarya Tip Dergisi 2019, 9(3):464-469)

Gereç ve Araștırma Kesitsel Tipte Tanımlayıı bir araștırmadır. Çalıșmaya kliniğimizde 2014 ile 2018 yılları arasında, atnalı böbreğinde taș bulunan ve PNL yapılan yedi hasta Yöntemler dahil edildi. Hastaların yas (yıl), cinsiyet, tas özellikleri (tas yüzey alanı, taraf ve lokalizasyon), operasyon süresi (dk), floroskopi süresi (dk), hemoglobin değișim miktarı, Hounsfield Ünitesi (HU) değerleri, nefrostomi alınma zamanı (gün), komplikasyonları ve rezidüel taşları değerlendirildi. Tüm hastalar için PNL genel anestezi altında prone pozisyonda gerçekleştirildi. Postoperatif 1. ayda, kontrastsız bilgisayarlı tomografi ile hastalar kontrol edildi. 4 mm'den büyük taşlar rezidü taş olarak kabul edildi.

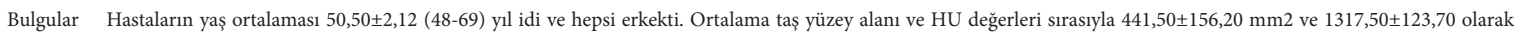
bulunmuștur. PNL yapılan hastaların ikisinde bașarısız ekstrakorporeal șok dalga litotripsi (extracorporeal shock wave lithotripsy =ESWL) öyküsü vardı. Ameliyat sırasında veya postoperatif dönemde hiçbir hastada majör komplikasyon gelişmedi. Toplam rezidü taş oranı 42,80\% (3/7).

Sonuç Bizim sonuçlarımıza göre, PNL operasyonu atnalı böbreklerde güvenli ve etkili bir şekilde uygulanabilir

Anahtar Atnalı böbrek; böbrek taşı; perkütan nefrolitotomi

Kelimeler

\begin{tabular}{|c|c|}
\hline \multicolumn{2}{|l|}{ Abstract } \\
\hline Objective & $\begin{array}{l}\text { THorseshoe kidney is the most common type of renal fusion abnormality. The most common complication of horseshoe kidney is renal stones. The aim of this study was to evaluate PNL surgery } \\
\text { outcomes on renal stones in patients with horseshoe kidney. (Sakarya Med J 2019, 9(3):464-469). }\end{array}$ \\
\hline $\begin{array}{r}\text { Materials } \\
\text { and Methods }\end{array}$ & $\begin{array}{l}\text { The study is cross-sectional and descriptive research. Between } 2015 \text { and 2018, we performed percutaneous nephrolithotomy (PNL) in seven patients for renal stones with HSK. We evaluated } \\
\text { patients age, gender, stones characteristics (stone surface area, side and localization), operation time (min.), fluoroscopy time, hemoglobin change amount, Hounsfield Unit (HU) values, } \\
\text { nephrostomy removal time, complications and residual stone. PNL was performed in prone position under general anesthesia in all patients. Postoperative } 1 \text { st month, patients controlled with } \\
\text { non-contrast computerized tomography (NCCT). Stones larger than } 4 \mathrm{~mm} \text { were accepted as residual stone. }\end{array}$ \\
\hline Results & $\begin{array}{l}\text { The mean age of the patients was } 50.50 \pm 2.12 \text { years (range } 48-69 \text { ), and all of them were males. The mean stone surface area and HU values were found to be } 441.50 \pm 156.20 \mathrm{~mm} 2 \text { and } \\
1317.50 \pm 123.70 \text { respectively. Two patients with underwent } P N L \text { had a history of extracorporeal shock wave lithotripsy (ESWL) failure. There were no mojor complication occurred during the } \\
\text { surgery or postoperative period. The overall residual stone rate was } 42.80 \% \text { (3/7). }\end{array}$ \\
\hline Conclusion & According to our results, the PNL can be performed to the horseshoe kidney safely and effectively \\
\hline Keywords & Horseshoe kidney; percutaneous nephrolithotomy; renal stones \\
\hline
\end{tabular}
}




\section{GIIRIș}

Atnalı böbrek en yaygın füzyon anomalisidir. Normal popülasyonda 400 ile 600 kişide bir görülür. ${ }^{1}$ İntrauterin yaşamın 4 ile 8 . haftalarında böbrek alt kutuplarının füzyonu sonucu her iki böbrek uygun rotasyonu yaparak yükselemez. Böbrek pelvisi normale göre önde kalır ve üreter böbrek pelvisine normal giriş yerinin daha üstünden girer. $\mathrm{Bu}$ durum böbreğin doğal drenajını bozarak staza yol acar. Ayrıca spontan olarak taş düşmesini de zorlaştırır. Bu kişiler böbrek taşı, hidronefroz ve idrar yolu enfeksiyonuna daha yatkındır. ${ }^{2}$ Atnalı böbreğe sahip olanların yaklaşı \% 21 - 60'ında taş hastalığı vardır. ${ }^{3}$

Günümüzde atnalı böbrekte taş hastalığı tedavisi için farklı tedavi yöntemleri uygulanabilmektedir. Taş boyutuna, taşların sayısına ve konumuna bağlı olarak bu yöntemler tercih edilmektedir. Günümüzde minimal invaziv cerrahinin yeri son derece önemlidir. Ekstrakorporeal şok dalga litotripsi (extracorporeal shock wave lithotripsy=ESWL), üreterorenoskopi ve perkütan nefrolitotomi (PNL) gibi yöntemlerin birlikte veya tek başına kullanılması ile atnalı böbreklerdeki taşsızlık oranı oldukça yüksektir. Özellikle 20 mm'den büyük taşları olan veya ESWL sonrası taşlarını düşüremeyen olgularda PNL etkili bir tedavi yöntemidir. Bu çalışmanın amacı, atnalı böbrek anomalisi olan hastalarda, böbrek taşlarının tedavisinde uygulanan PNL cerrahisinin sonuçlarını değerlendirmektir.

\section{GEREÇ ve YÖNTEMLER}

Araştırma Kesitsel Tipte Tanımlayıcı bir araştırmadır. Çalışmaya kliniğimizde 2014 ile 2018 yılları arasında, atnalı böbrek anomalisine eşlik eden taş hastalığı nedeniyle PNL operasyonu yapılan yedi hasta dahil edildi. Çalışma Sakarya Üniversitesi Tip Fakültesi Etik Kurul (26.02.2019 tarihli ve 71522473/050.01.04/26 karar numaral1) onayı ile Helsinki Deklarasyonu kurallarına uygun olarak hazırland. Hastaların yaş (yll), cinsiyet, taş özellikleri (taş yüzey alanı, taraf ve lokalizasyon), operasyon süresi (dk), floroskopi süresi (dk), hemoglobin değişim miktarı, Hounsfield Ünitesi (HU) değerleri, nefrostomi alınma zamanı (gün), komplikasyonları ve rezidüel taşları değerlendirildi.

Operasyon öncesinde, idrar tahlili, böbrek fonksiyon testleri, tam kan sayımı ve koagulometri parametreleri, idrar kültürü ve duyarlılık testlerini içeren preoperatif laboratuar testleri tüm hastalara yapıldı. İdrar yolu enfeksiyonu (IYE) olan hastalar işlem öncesi uygun bir antibiyotik rejimi ile tedavi edildi. Tüm hastalara operasyon öncesinde profilaktik antibiyotik yapıldı. Hastaların hepsinde PNL işlemi genel anestezi altında yapıldı. Litotomi pozisyonunda açık uçlu üreter kateteri böbrek pelvisine ya da üreter üst uçuna kadar ilerletilerek yerleștirildi. Üreter katateri takılmasını takiben hastalar prone pozisyonuna alındı. C kollu floroskopi eşliğinde $18 \mathrm{G}$ metal iğne kullanılarak böbrek toplayıcı sistemine üst polden giriş sağlandı. Giriş iğnesi içerisinden kılavuz tel toplayıcı sisteme yerleştirildi. Ardından amplatz dilatasyon seti ile $10 \mathrm{~F}$ dilatatör kullanılarak fasiyal dilatasyonu takiben ardışı olarak 30F'e kadar dilatasyon yapıldı. Ardından akses sheat yerleştirilerek dilatasyon tamamlandı. Toplayıcı sisteme 26F rijit nefroskopla giriş sağlanmasının ardından pnomötik litototriptörler aracılı̆̆ı ile taşlar fragmente edildi. Taşların forseps aracilığ ile çıkarılmasının ardından tüm hastalara $18 \mathrm{~F}$ re-entery nefrostomi katateri yerleştirildikten sonra işlem sonlandırıldı.

Tüm hastalar için PNL genel anestezi altında prone pozisyonda gerçekleştirildi. Tüm taşlar pnömatik litotriptör kullanılarak parçalandı. Komplikasyon değerlendirmesi modifiye Clavien sınıflandırma sistemi kullanılarak yapıld. Postoperatif 1. ayda, kontrastsız bilgisayarlı tomografi ile hastalar kontrol edildi. 4 mm’den büyük taşlar rezidü taş olarak kabul edildi. Her hastanın kontrastsız bilgisayarlı tomografi (BT) kesitleri incelendi ve ortalama HU ölçüldü. Her bir taş için üç enine kesit (üst, orta ve alt) tanımlanmıştır. Her bir kesit için region of interest (ROI) elde edilmiş ve ortalama HU değeri üç ROI ortalaması ile hesaplanmıştır. Taş yüzey alanı aşağıdaki formül kullanılarak hesaplanmıştır: (Maksimum uzunluk (mm) x Maksimum genişlik (mm) $x \pi \times 0,25)$. Hastaların operasyon öncesi ve 


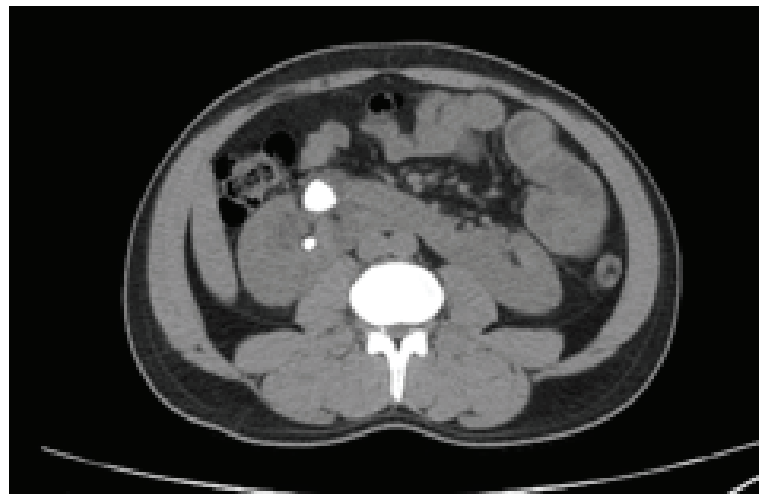

Resim 1. Hastalardan birinin operasyon öncesine ait bilgisayarlı tomografi görüntüsü

sonrası örnek BT görüntüleri Resim 1 ve 2 gösterilmiştir.

\section{BULGULAR}

Hastaların yaş ortalaması 50,50 $\pm 2,12$ yıl (aralık 49-68) idi ve hepsi erkekti. Ortalama taş yüzey alanı ve HU değerleri sirasiyla $441,50 \pm 156,20 \mathrm{~mm}^{2}$ ve $1317,5 \pm 123,70$ olarak bulunmuştur. PNL yapılan hastaların ikisinde başarısız ESWL öyküsü vardı. Tüm hastalarda toplayıcı sisteme üst polden ve subkostal olarak girildi. Ortalama operasyon süresi 122 dk idi. Ortalama Hb değişimi 3,70 idi. Bir hastaya postoperatif dönemde kan transfüzyonu yapıldı. İki hastada postoperatif ateş görüldü. Ameliyat sırasında veya

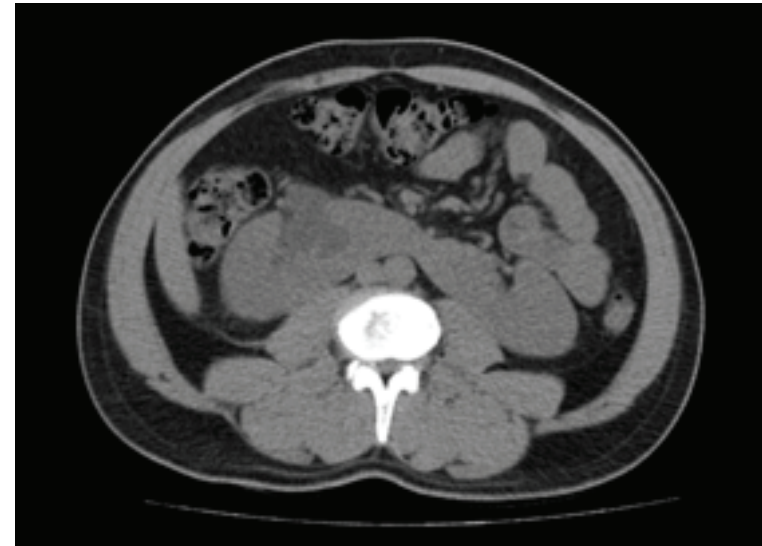

Resim 2. Aynı hastaya ait operasyon sonrası 1. ay bilgisayarlı tomografi görüntüsü

postoperatif dönemde majör komplikasyon gelişmedi. Toplam rezidü taş oranı \%42,80 idi (3/7). Hiçbir hastaya postperatif dönemde ESWL yapılmadı. Hastalar, taş özellikleri, operasyon verileri ve sonuçları Tablo 1'de verilmiştir.

\section{TARTIŞMA}

Atnalı böbrekler üç anatomik anormallik ile karakterizedir; ektopi, malrotasyon ve vasküler değişikler. Bu böbreklerde; alt poller daha mediyalde bir istmus ile birleşiktir, pelvis ve üreterler istmusa kıyasla arkada, öne dönüktür. Çoğunlukla kaliksler normal sayıda olmakla birlikte, anor-

\begin{tabular}{|c|c|c|c|c|c|c|c|}
\hline & Hasta 1 & Hasta 2 & Hasta 3 & Hasta 4 & Hasta 5 & Hasta 6 & Hasta 7 \\
\hline Yaş (yıl) & 52 & 50 & 36 & 46 & 66 & 68 & 43 \\
\hline Taş yüzey alanı $(\mathrm{mm} 2)$ & 552 & 313 & 329 & 379 & 373 & 410 & 331 \\
\hline Taş Dansitesi (HU) & 1405 & 926 & 1494 & 537 & 1238 & 1444 & 1230 \\
\hline Taş tarafı & sağ & sol & sol & sağ & sağ & sağ & sağ \\
\hline Operasyon süresi (dk) & 140 & 120 & 135 & 110 & 114 & 120 & 115 \\
\hline Taş lokalizasyonu & Pelvis & $\begin{array}{l}\text { Pelvis ve } \\
\text { alt kaliks }\end{array}$ & $\begin{array}{l}\text { Pelvis ve } \\
\text { alt kaliks }\end{array}$ & $\begin{array}{l}\text { Pelvis, alt ve } \\
\text { orta kaliks }\end{array}$ & Pelvis & $\begin{array}{l}\text { Pelvis ve } \\
\text { alt kaliks }\end{array}$ & $\begin{array}{l}\text { Pelvis ve } \\
\text { alt kaliks }\end{array}$ \\
\hline Hastanede kalış süresi (gün) & 1 & 2 & 4 & 3 & 1 & 4 & 3 \\
\hline Skopi süresi (dk) & 2,80 & 3,50 & 3,20 & 2,40 & 5,20 & 2,60 & 2,30 \\
\hline Nefrostomi alınma zamanı (gün) & 1 & 1 & 3 & 2 & 1 & 3 & 3 \\
\hline Rezidüel taş & yok & var & yok & yok & yok & var & yok \\
\hline Komplikasyon* & 0 & 0 & Grade 1 & 0 & 0 & Grade 1 & Grade 2 \\
\hline
\end{tabular}


mal rotasyon ile posteriyora dönüktür. Üreterler malrotasyon nedeni ile pelvise yüksek girişli ve lateralizedir. Hastalık erkeklerde iki kat daha fazla görülür. ${ }^{4}$ Olguların yaklaşı üçte biri asemptomatiktir ve bunlar radyolojik görüntülemelerde insidental olarak saptanırlar. Atnalı böbrekte üreterin yüksek insersiyonu, deforme olmuş üreteropelvik bileşke ve idrar drenajının bozulması vakaların \%60-\%70'ini içeren hidronefroz, staz ve böbrek taşı oluşumundan sorumludur. ${ }^{5}$

ESWL böbrek taşlarının tedavisinde non invaziv, güvenli ve başarılı bir tedavi metodudur. Genellikle $2 \mathrm{~cm}$ den küçük taşlarda tercih edilir. ESWL başarı oranları literatürde $\% 27,80$ ile $\% 75,90$ arasında bildirilmektedir. ${ }^{6-8}$ Ray ve ark.'larının serilerinde atnalı böbrekli hastalarda ESWL genel başarı oranını \% 63,60, genel taşsızlık oranını ise \%39,10 olarak bildirmişlerdir. Bu hastaların \%73’ü PNL, URS gibi ek tedavi yöntemlerine ihtiyaç duymuşlardır. ${ }^{8}$ ESWL başarısının normal anatomiye sahip böbreklere göre daha az olmasının birçok nedeni vardır. Taş boyutu bu konuda önemli faktördür. Sheir ve ark. çalışmalarında 15 mm'den küçük taşlarda başarı oranı \%79 iken, taş boyutu 15 mm'den büyük olanlarda başarı oranın \%53 olarak bildirmişlerdir. ${ }^{9}$ Kalikslerin posteriyora yerleşimi, alt kalikslerin pozisyonu, böbreklerin normalden daha önde oluşu nedeniyle cilt taş mesafesinin uzun olması, böbrek drenajının yetersiz oluşu ve taş fragmanlarının zor düşmesi ESWL başarısı için diğer olumsuz faktörlerdir. ${ }^{10}$ Bizim hastalarımızın ortalama taş boyutu $383,80 \mathrm{~mm}^{2}$ idi ve ikisinde $(\% 28,50)$ başarısız ESWL öyküsü vardı.

Günümüzde fleksible üreterorenoskoplar ile atnalı böbreklerde retrograd intrarenal cerrahi (RIRS) uygulanabilmektedir. RIRS ile orta boy böbrek taşlarında taşsızlık oranları \%70-89 arasındadır. ${ }^{10-12}$ RIRS başarısında taşın boyutu ve taşın lokalizasyonu oldukça etkilidir. Atış ve ark.'larının çalışmalarında RIRS başarısı \%70 olarak bildirilmiştir. ${ }^{10}$ $\mathrm{Bu}$ çalışmada alt pol taşları ve $20 \mathrm{~mm}$ den büyük taşların RIRS için olumsuz faktörler olduğu vurgulanmıştır. Fleksible nefroskop kullanımı ek girişim oranının azalttığı, taşsızlık oranını artırdığı ve komplikasyonları azalttığı savunulmaktadır. ${ }^{10,13}$ Miller ve ark. çalışmalarında normal nefroskop bakışı ile taşsızlık oranını \%84,10 olduğunu aynı olgulara rutin olarak fleksible nefroksop ile ikinci kez bakıldığında taşsızlık başarısının \%93,20 olduğunu bildirmişlerdir. ${ }^{13}$ Kliniğimizde fleksible nefroksop bulunmad1ğından hiçbir hastada kullanılmamıştır.

Büyük (> $2 \mathrm{~cm}$ ) böbrek taşlarında normal böbreklerde olduğu gibi atnalı böbreklerde de standart tedavi yöntemi PNL'dir. ${ }^{5}$ Anormal anatomik yapı, toplayıcı sisteme perkütan olarak yapılacak girişimleri zorlaştırmaktadır. Bu konuda özellikle iki ana faktör öne çıkmaktadır; böbreğin damar desteği ve toplayıcı sistemin pozisyonu. Atnalı böbreklerde anormal pozisyonel anatomiye rağmen, renal damarlar hilusa anteromedialden girer ve kaliksiyel yap1lar posteriora yönlenmiştir. Bu nedenle giriş sağlanırken damar yaralama riski normal böbreklere göre çok daha yüksek değildir. ${ }^{14}$ Atnalı böbreklerde üst pol girişi tüm kalikslere, renal pelvise ve proksimal üretere rahat ulaşlabilmeyi sağlar. Bununla birlikte, üst pol girişi orta ve alt kaliksiyel yapılara ulaşmak için normale göre daha uzun bir yol geçilmesini gerektirir. Bu endoskopik enstrümanların yetersizliğine neden olabilir. Özellikle obez hastalarda bu durum daha da belirginleşir. Uzun ve fleksible nefroskoplar bu olgularda faydalı olabilir. ${ }^{15}$

Literatürde üst pol girişi \% 48 ile \% 100 arasında bildirilmektedir. ${ }^{13,16,17}$ Bizim çalışmamızda tüm hastalara üst pol girişi yapılmıştır. Normal anatomili hastalarda böbreğe üst polüne 12. kot üzerinden girişi tercih edilmektedir. Bu durumda toraks komplikasyonları daha sık görülebilmektedir. ${ }^{18}$ Öte yandan atnalı böbrekli hastalarda böbreğin inferiora yerleşimli olması nedeniyle plevradan uzaklaşılmakta ve üst pol girişleri göreceli olarak güvenli olmaktadır. Raj ve arkadaşları \%62,50'ini üst pol girişi yaptıkları atnalı böbrekli PNL serilerinde sadece bir hastada (\% 6) torasik komplikasyon bildirmişlerdir. ${ }^{19}$ Majör genel komplikasyon oranı ise \% 12,50 olarak bildirilmektedir. Liatsikos ve ark. en sık majör komplikasyonun masif kanama 
olduğunu (\%20), en sık minör komplikasyonun ise üriner enfeksiyon olduğunu $(\% 26,60)$ bildirmişlerdir. ${ }^{20}$ Miller ve ark. ise genel komplikasyon oranını \%14,30 olarak bildirmişlerdir. ${ }^{15}$ Atnalı böbreklerde kolon posterolateral veya retrorenal pozisyona daha yatkındır. Bu nedenle kolon yaralanmaları göreceli olarak normale göre daha yüksektir. ${ }^{21}$ Preoperatif radyolojik değerlendirme bu noktada anahtar rol oynamaktadır. Özellikle bilgisayarlı tomografi ile yapılan değerlendirme hem toplayıcı sistem anatomisi hem de komşu organların değerlendirilmesini sağlar. Bizim çalışmamızda kolon veya toraks yaralanması gibi majör bir komplikasyon ile karşılaşılmamıştır.

\section{SONUÇ}

Bizim sonuçlarımıza göre, PNL atnalı böbreklerde düşük komplikasyon oranlarıyla güvenle uygulanabilir bir yöntemdir.

\section{Çıkar çatışması}

Yazarlarla ya da yazı ile ilgili bildirilen herhangi bir çıkar çatışması yoktur. 
Sakarya Tip Dergisi 2019;9(3):464-469

AYDEMIR ve Ark. Atnalı Böbreklerde Perkütan Nefrolitotomi Deneyimlerimiz

\section{Kaynaklar}

1. Weizer AZ, Silverstein AD, Auge BK, Delvecchio FC, Raj G, Albala DM, et al. Determining the incidence of horseshoe kidney from radiographic data at a single institution. J Urol 2003;170(5):1722-1726.

2. Bauer S. Anomalies of the upper urinary tract. In: Walsh PC, Retic AB, Vaughan ED, et al. ed. Campbell's Urology, 8th ed. Philadelphia: Elsevier Saunders. 2002. s:1885-1913.

3. Yohannes $P$, Smith $A D$. The endourological management of complications associated with horseshoe kidney. J Urol 2002;168:5-8.

4. Ongeti, K. W, Ogeng'o, J, Saidi, H. A horseshoe kidney with partial duplex systems. Int J Anat Var 2011;4:55-56.

5. Cussenot O, Desgrandchamps F, Ollier P, Teillac P, Le Duc A. Anatomical bases of percutaneous surgery for calculi in horseshoe kidney. Surg Radiol Anat 1992;14(3):209-213.

6. Lampel A, Hohenfellner M, Schultz-Lampel D, Lazica M, Bohnen K, ThürofJW. Urolithiasis in horseshoe kidneys: Therapeutic management. Urology 1996;47(2):182-186.

7. Kirkali Z, Esen AA, Mungan MU. Effectiveness of extracorporeal shockwave lithotripsy in the management of stone-bearing horseshoe kidneys. J Endourol 1996;10(1):13-15.

8. Ray AA, Ghiculete D, D'A Honey RJ, Pace KT. Shockwave lithotripsy in patients with horseshoe kidney: determinants of success. J Endourl 2011;25(3):487-493.

9. Sheir, K.Z., K. Madbouly, E. Elsobky, Abdelkhalek M. Extracorporeal shock wave lithotripsy in anomalous kidneys: 11-year experience with two second-generation lithotripters. Urology 2003;62(1):10-15.

10. Atis G, Resorlu B, Gurbuz C, Arikan O, Ozyuvali E, Unsal A, et al. Retrograde intrarenal surgery in patients with horseshoe kidneys. Urolithiasis 2013;41(1):79-83.

11. Molimard B, Al-Qahtani S, Lakmichi A, Sejiny M, Gil-Diez de Medina S, Carpentier $X$, et al. Flexible ureterorenoscopy with holmium laser in horseshoe kidneys. Urology 2010;76(6):1334-1337
12. Chouaib A, Al-Qahtani S, Thoma A, Cordier G, Merlet B, Gil-Diez S, et al. Horseshoe kidney stones: benefit of flexible ureterorenoscopy with holmium laser. Prog Urol 2011;21(2):109-113.

13. Miller NL, Matlaga BR, Handa SE, Munch LC, Lingeman JE. The presence of horseshoe kidney does not affect the outcome of percutaneous nephrolithotomy. J Endourol 2008;22:12191225

14. Janetschek G, Kunzel KH. Percutaneous nephroliาthotomy in horseshoe kidneys. Applied anatomy and clinical experience. Br J Urol 1988;62:117-122.

15. Shokeir AA, El-Nahas AR, Shoma AM, Eraky I, El-Kenawy M, Mokhtar A, et al. Percutaneous nephrolithotomy in treatment of large stones within horseshoe kidneys. Urology 2004;64(3):426-429.

16. Symons SJ, Ramachandran A, Kurien A, Baiysha R, Desai MR. Urolithiasis in the horseshoe kidney: a single-centre experience. BJU Int. 2008;102:1676-1680.

17. Satav V, Sabale V, Pramanik P, Kanklia SP, Mhaske S. Percutaneous nephrolithotomy of horseshoe kidney: Our institutional experience. Urol Ann. 2018;10(3):258-262.

18. Kyriazis I, Panagopoulos V, Kallidonis P, Özsoy M, Vasilas M, Liatsikos E. Complications in percutaneous nephrolithotomy. World J Urol 2015;33(8):1069-1077.

19. Raj GV, Auge BK, Weizer AZ, et al. Percutaneous management of calculi within horseshoe kidneys. J Urol 2003;170:48-51.

20. Liatsikos EN, Kallidonis P, Stolzenburg JU, Ost M, Keeley F, Traxer, et al. Percutaneous management of staghorn calculi in horseshoe kidneys: a multiinstitutional experience. $J$ Endourol 2010;24:531-536.

21. El-Nahas AR, Shokeir AA, El-Assmy AM, Shoma AM, Eraky I, El-Kenawy MR, et al. Colonic perforation during percutaneous nephrolithotomy: study of risk factors. Urology 2006;67(5):937-941. 